Infusiontherapie 1991;18(suppl 1):1

\title{
Impressum, Vol. 18, Suplement 1, 1991
}

\section{Herausgeber}

\section{S. KARGER}

Verlag für Medizin und Naturwissenschaften GmbH,

Postfach 1724, D-8034 Germering

Presserechtlich verantwortlich: Walter Kunz, Gesellschafter

Offizielles Organ der Deutschen Gesellschaft für Transfusionsmedizin und Immunhämatologie

ilПlAKE

$3 / 4^{3} / 8 \Lambda$ Y für klinische

\section{$\wedge \wedge \wedge \wedge 5 / 8$ B $\Psi$ Ernährung}

Offizielles Organ

der Österreichischen Arbeitsgemeinschaft

für klinische Ernährung (AKE)

Gründungsherausgeber

H. Reissigl, W. Hofrat, Innsbruck

Schriftleitung

A. Grünert, Ulm V. Kretschmer, Marburg W. Stangel, Hannover K. Widhalm, Wien G.

Wolfram, München

Wissenschaftlicher Beirat

M. Adolph, Augsburg

F.W. Ahnefeld, Ulm

K.H. Bäßler, Mainz

W. Behrendt, Aachen

H. Bergmann, Linz

C. Bode, Köln

H. Böhles, Frankfurt

P. Deetjen, Innsbruck

W. Dick, Mainz

R. Dölp, Fulda

H. von Domarus, Lübeck

W. Druml, Wien

J. Eckart, Augsburg

P. Ferenci, Wien

H. Förster, Frankfurt

R. Glaser von Roman, Düsseldorf

A. Grünert, Ulm

J.M. Hack1, Innsbruck

W. Haider, Wien

M. Halmágyi, Mainz W. Hartig, Leipzig 0. Heidenreich, Aachen U. Henneberg, Berlin 


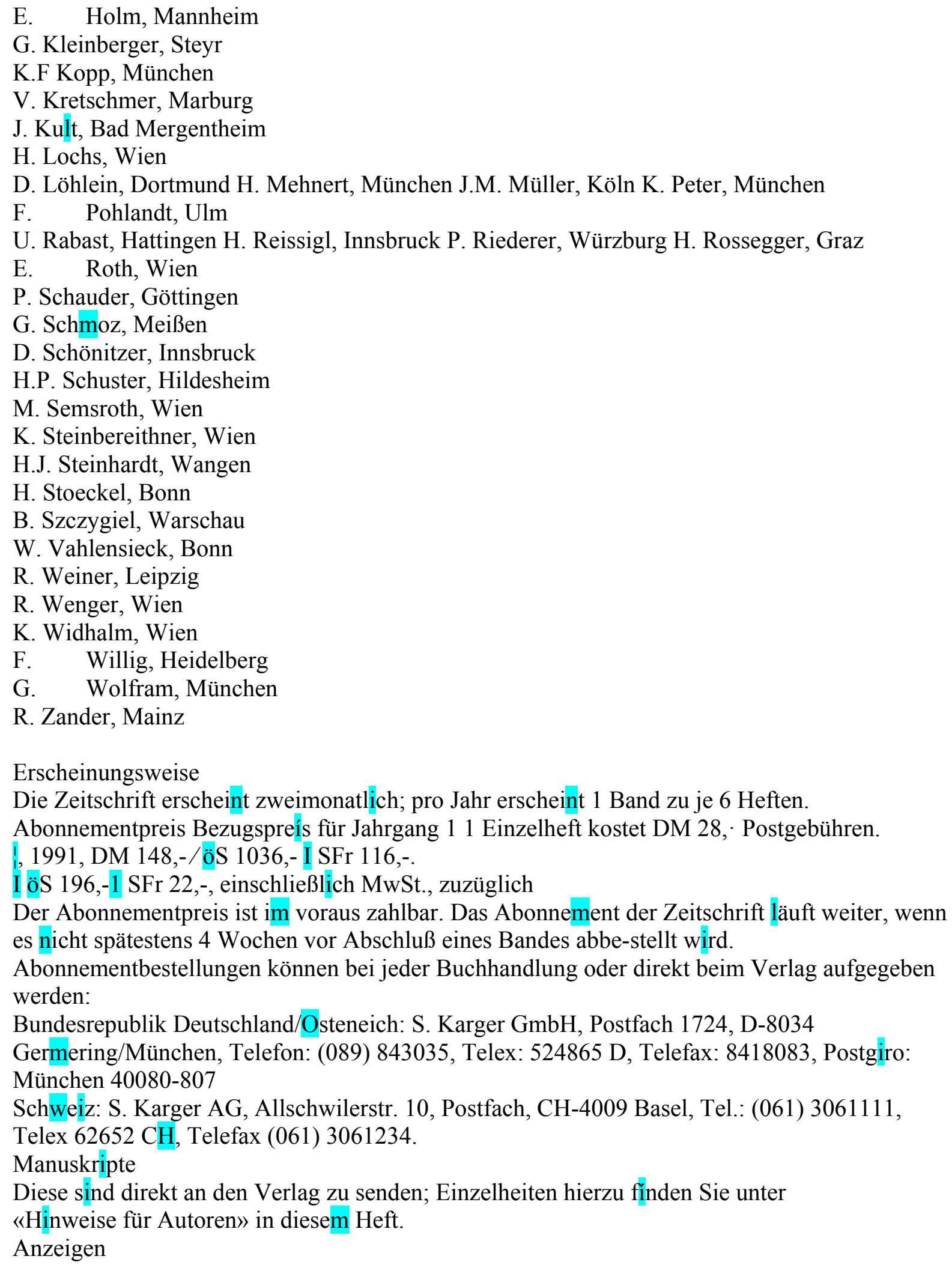


S. Karger Verlag für Medizin und Naturwissenschaften GmbH, Postfach 1724, D-8034 Germering, Telefon (089) 843035. Gültig ist die Preisliste Nr. 9 vom 1.10.1990.

Für den Inhalt außerhalb des redaktionellen Teiles (insbesondere Anzeigen, Industrieinformationen, Pressezitate und Kongreßinformationen usw.) überneh-men Schriftleitung, Beirat und Verlag keine Gewähr.

Eine Markenbezeichnung kann warenzeichenrechtlich geschützt sein, auch wenn bei IhrerVerwendung in dieser Zeitschrift das Zeichen ${ }^{\circledR}$ oderein andererHinweis auf etwa bestehende Schutzrechte fehlen sollte. Für Satzfehler, insbesondere bei Dosierungsangaben, wird keine Gewähr übernommen.

Alle Rechte, insbesondere das Recht der Vervielfáltigung und Mikrokopie sowie der Übersetzung, vorbehalten. Nachdruck, auch auszugsweise, nur mit Geneh-migung des Verlages. Fotokopien dürfen nur für den persönlichen Gebrauch als Einzelkopien hergestellt werden. Jede im Bereich eines gewerblichen Unterneh-mens zulässig hergestellte oder benutzte Kopie dient gewerblichen Zwecken gem. § 54(2) UrhG und verpflichtet zur Gebührenzahlung an die Verwertungs-gesellschaft WORT, Abt. VG Wissenschaft, Goethestr. 49, D-8000 München 2. (C) Copyright 1991 by S. Karger, Verlag für Medizin und Naturwissenschaften GmbH, Postfach 1724, D-8034 Germering ISBN 3-8055-5444-3

Verlagsleitung: Manfred Just Redaktíonsassistenz: Anne Schieber Anzeigenverkauf: Marlene Scholz Anzeigenverwaltung: Eva Lindenau Herstellung: Horst H. Bruch Vertrieb: Gabriela Taube

Satz und Druck: Bonitas-Bauer, Grafischer Betrieb, Max-von-Laue-Str. 31, D-8700 Würzburg. KARGER 1991;018:1 